\title{
Shortcomings of cross polarisation prediction methods for reflector antennas
}

\author{
Bach, H.; Viskum, H.-H.
}

Published in:

Antennas and Propagation Society International Symposium

Publication date:

1986

Document Version

Publisher's PDF, also known as Version of record

Link back to DTU Orbit

Citation (APA):

Bach, H., \& Viskum, H-H. (1986). Shortcomings of cross polarisation prediction methods for reflector antennas. In Antennas and Propagation Society International Symposium (pp. 271-274). IEEE.

\section{General rights}

Copyright and moral rights for the publications made accessible in the public portal are retained by the authors and/or other copyright owners and it is a condition of accessing publications that users recognise and abide by the legal requirements associated with these rights.

- Users may download and print one copy of any publication from the public portal for the purpose of private study or research.

- You may not further distribute the material or use it for any profit-making activity or commercial gain

- You may freely distribute the URL identifying the publication in the public portal

If you believe that this document breaches copyright please contact us providing details, and we will remove access to the work immediately and investigate your claim. 


\title{
SHORTCOMINGS OF CROSS POLARISATION \\ PREDICTION METHODS FOR REFLECTOR ANTENNAS
}

\author{
H. Bach H.-H. Viskum \\ Electromagnetics Institute \\ Technical University of Denmark \\ DK-2800 Lyngby, Denmark
}

Introduction. The still increasing requirements to satellite reflector antennas, in particular with respect to such parameters as cross polarisation and side lobe level, imply a demand for fast and accurate analysis methods by which the performance of the reflectors can be predicted. One such approach is the SNFGTD method [Bach et al., (1981)] in which the near field from the reflector is calculated on a sphere by using the GTD, and transformed into the far field by using a spherical expansion. In the near field the advantages of ray optics may be fully exploited, since the caustic of reflected rays, which in the far field occurs in the main beam direction, does not exist close to the antenna. For example, the ray description allows a rigorous treatment of blockage from feed or subreflector, simply by tracing the rays through the system, while physical optics (PO) relies on a truncation of the induced currents in shadowed regions. In addition, since the near-field to far-field transformation makes use of the FFT [Larsen, (1980)], SNFGTD will in many cases be superior to PO with respect to computer time.

Comparison between SNFGTD, PO and the moment method. To explore the accuracy of the SNFGTD method we have applied it to a very simple antenna configuration, namely a rotationally symmetric paraboloid with a Huygens' source or a Hertz dipole, respectively, as primary feed. Furthermore, the induced current version of PO [GRASP6, Jørgensen (1983)] and the moment method (MM) were applied. The MM solution is assumed to provide the most accurate results of the three methods, but does not in general constitute an alternative to the other two, because of its heavy CPU-time requirement.

The three methods were found to yield practically identical results, as so far the copolar patterns and directivities are concerned. In Table 1 the directivities are listed and it is seen, that the largest deviation is $0.08 \mathrm{~dB}$ for the Huygens' source feed case. No MM results are provided for the 40 wavelength diameter reflector, again due to CPU-time. An example of the agreement of the copolar patterns is shown in fig. 1. where we have plotted the E-plane pattern from a reflector of diameter 20 wavelengths.

\begin{tabular}{|l|ccc|ccc|}
\hline \multicolumn{1}{|c|}{ Feed } & \multicolumn{3}{|c|}{ Huygens' source } & \multicolumn{3}{c|}{ Dipole source } \\
\cline { 1 - 6 } Diameter & SNFGTD & MM & PO & SNFGTD & MM & PO \\
\hline $10 \lambda$ & 27.83 & 27.77 & 27.83 & 24.74 & 24.71 & 24.75 \\
$20 \lambda$ & 33.81 & 33.87 & 33.79 & 30.76 & 30.79 & 30.82 \\
$40 \lambda$ & 39.81 & - & 39.81 & 36.80 & - & 36.80 \\
\hline
\end{tabular}

Table 1. Calculated directivities (dBi) for paraboloids of diameter 10,20 and $40 \mathrm{~A}$. 
Fig. 2 shows cross polar patterns for the 20 wavelengths reflector fed by a dipole and a Huygens' source, respectively. In the first case, the cross polar component is mainly due to the feed itself and is equally well predicted by the three methods. In the second case, the feed radiates a purely copolarised field, and the depolarisation is caused by the edge of the reflector. We see, that the Po results, in which fringe currents are not included, differ significantly from the other two, while SNFGTD and MM are in good agreement except for the level of the first cross polar lobe.

To unveil the reason for SNFGTD and MM to differ in the first lobe, an inverse transformation was performed, that is the SNIFT-program [Larsen (1978)] was used to transform the MM data into the near field on a sphere of radius 16 wavelengths. The near field was also calculated using the GTD, and a careful comparison between the two patterns was carried out. A slight discrepancy occurs for $300<\theta<40^{\circ}$ as may be seen from fig. 3. This region is of interest, as it appears from fig. 4 , since the reflection boundary is at $\theta=380$. We therefore conclude that the GTD calculations using Kouyoumjian's diffraction coefficients are slightly inaccurate close to the reflection boundary were the transition function is significantly different from 1 . To further verify this, we substituted the GTD near-field data for $300<\theta<400$ with the corresponding MM near field data, transformed the resulting data into the far field and obtained the cross polar patterns shown in fig. 5 where the level of the first lobe is now correctly predicted using the SNFGTD method.

Conclusion. The detailed study of SNFGTD, PO and MM has shown that the copolar pattern is equally well predicted by any of the three methods, and the choice of technique for copolar pattern prediction needs therefore not be guided by an accuracy requirement but rather by what is the most practical to apply to the antenna configuration of interest. If the major concern is accurate calculation of small cross polarised field components mainly generated by the reflector surface, SNFGTD seems to be superior to PO when this is not supplemented with PTD. SNFGTD may be slightly inaccurate in certain directions, however, and it would be of interest to supply the GTD calculation of the near field close to the reflection boundary with the uniform asymptotic theory (UAT) of Ahluwalia, Lewis and Boersma.

\section{References}

Bach, H. Frandsen, A. \& Larsen, F.H.,

"Pattern Prediction for a Focused Reflector Antenna using GTD and Near-Field to Far-Field Transformation",

Proceedings of the ICAP-81, IEE Conference Publication No. 195, 1981.

Jørgensen, R.

"Manual for GRASPG"

Report No. 5-175-06, TICRA A/S Copenhagen, 1983.

Larsen, F.H.,

"SNIFTC-Mánual",

Electromagnetics Ínstitute, TUD, R 201، 1978.

Larsen, F.H.,

"Probe-corrected spherical near-field antenna measurements",

Electromagnetics Institute, TUD, LD 36, 1980. 

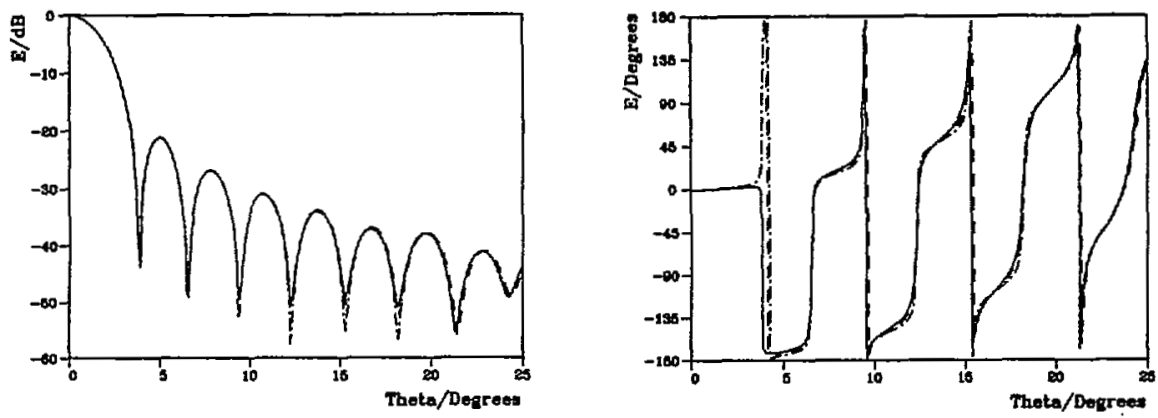

Fig. 1. E-plane pattern, amplitude and phase, for a $20 \lambda$ paraboloid. SNFGTD, - - - moment method, -...- physical optics

Parabolic Reflector Antenna

$\mathrm{D}=20 \lambda, F / D=0.4$

Dipole source

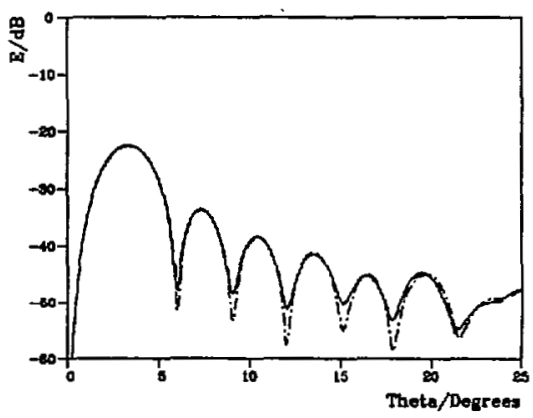

Hurgens Source



Fig. 2. Cross polar patterns for a dipole fed (left) and a Huygens' source fed (right) paraboloid. SNFGTD, - - MM, -...- PO: 
Parabolic Reflector Antenna

$D=20 \lambda, 8 / D=0.4$, Huygens Source

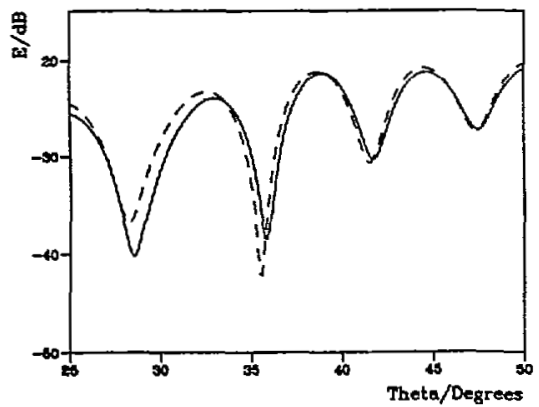

Fig. 3. Cross polar near field pattern. - SNFGTD, - - MM.

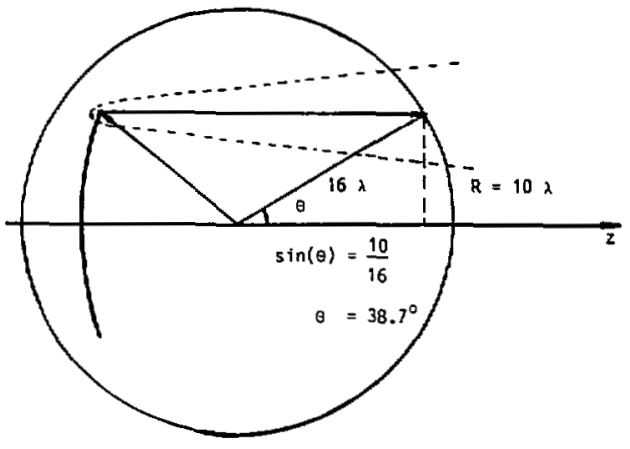

Fig. 4. Reflection boundary for the $20 \lambda$ reflector on a $16 \lambda$ sphere. The dashed curve indicates the transition region.
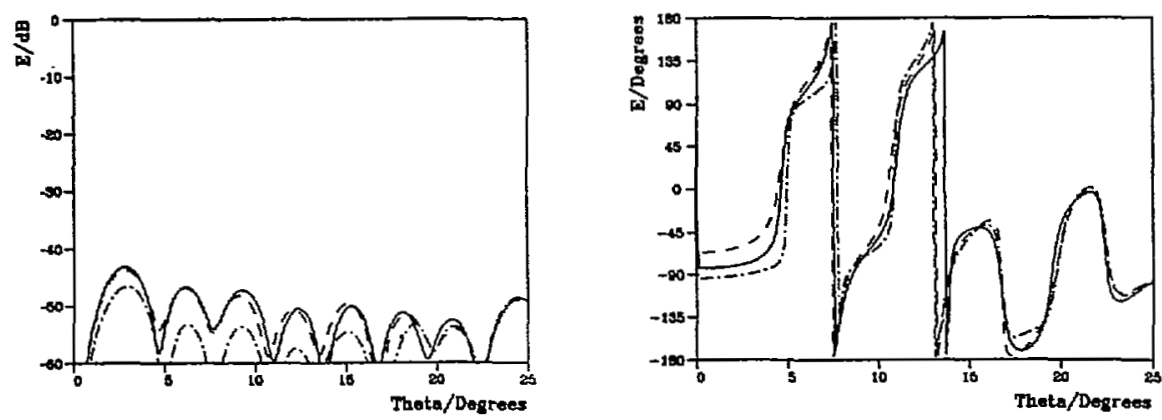

Fig. 5. Far-field cross polar pattern, amplitude and phase, when GTD nearfield data for $30^{\circ}<\theta<40^{\circ}$ are substituted by MM data. SNFGTD,

- - MM, ....- PO. 